\title{
Oxidation of Catechol using Titanium Silicate (TS-1) Catalyst: Modeling and Optimization
}

\author{
Sonali Sengupta*, Debarpita Ghosal, Jayanta K. Basu \\ Department of Chemical Engineering, Indian Institute of Technology Kharagpur, 721302, India
}

Received: 22nd April 2013; Revised: 25th October 2013; Accepted: 1st November 2013

\begin{abstract}
The oxidation of catechol was studied in an eco-friendly process with commercial titanium silicate-1 (TS-1) catalyst and hydrogen peroxide as oxidant in absence of all mass transfer effects. The process was optimized by Box-Behnken design in terms of three independent process variables such as reaction temperature, moles of hydrogen peroxide per mole of catechol and catalyst amount whose optimum values of the process variables were found to be $60{ }^{\circ} \mathrm{C}, 13.2$ and $1.24 \mathrm{~g}$ respectively for maximum conversion of $75.8 \%$. The effects of different process parameters such as mole ratio of hydrogen peroxide to catechol, catalyst particle size, catalyst amount, temperature and reaction time were studied. A pseudo first order kinetic model was fitted with the experimental rate data. The apparent activation energy for the reaction was found to be $11.37 \mathrm{~kJ} / \mathrm{mole}$. (C) 2013 BCREC UNDIP. All rights reserved
\end{abstract}

Keywords: Catechol; oxidation; TS-1; Box-Behnken design; kinetic study

How to Cite: Sengupta, S., Ghosal, D., Basu, J.K. (2013). Oxidation of Catechol using Titanium Silicate (TS-1) Catalyst: Modeling and Optimization. Bulletin of Chemical Reaction Engineering \& Catalysis, 8 (2): 167-177. (doi:10.9767/bcrec.8.2.4759.167-177)

Permalink/DOI: http://dx.doi.org/10.9767/bcrec.8.2.4759.167-177

\section{Introduction}

The green process development includes the manufacture of fine chemicals as well as the reduction or elimination of formation of the hazardous and undesirable byproducts [1-5]. Different catalysts, solvents, oxidizing or reducing agents and process conditions, alone or in combination, can help to make a process environmentally green.

Titanium silicate catalyst, is an excellent oxidation catalyst for different fine chemicals production in combination with hydrogen peroxide as green

* Corresponding Author.

E-mail: sonalis.iitkgp@gmail.com (S. Sengupta) oxidizing agent [6-8].This is the most versatile catalyst in oxidation reactions like epoxidation of olefins, e.g. allyl chloride [9], the hydroxylation of aromatic hydrocarbons [10], oxidation of aliphatic $\mathrm{C}-\mathrm{H}$ bonds, i.e., saturated hydrocarbons [11], the ammoxidation of ketones [12]. TS-1 can also be used for clean processes like the oxidation of secondary amines, alcohols, thioethers and sulfoxides with hydrogen peroxide as the oxidant [13-15]. Ecofriendly synthesis of heterocyclic $N$-oxides using $30 \% \mathrm{H}_{2} \mathrm{O}_{2}$ and TS- 1 catalyst gives a good yield with water as the by-product [16].

The liquid phase oxidation of 2-octanol was studied and kinetics of the reaction was reported [17]. The oxidation of catechol was studied in presence of metalloenzymes as a catalyst [18]. The aerobic oxidation of catechol by polyphenol oxidase as 
catalyst in presence of aniline gives ortho-quinone as the initial product [19]. Catechol oxidation was studied using $\mathrm{Cu}(\mathrm{II})$ complex as catalyst using molecular oxygen [20]. Silica supported $\mathrm{Cu}(\mathrm{II})$ complex was reported as a catalyst for the aerial oxidation of catechol [21]. Oxidation of catechol in the presence of $\mathrm{H}_{2} \mathrm{O}_{2}$ was studied using ruthenium complexes as catalysts [22].

The use of TS-1 as catalyst for the oxidation of alkanes, alkenes and aromatic hydrocarbons with hydrogen peroxide were carried out under mild conditions [23]. Large pore Ti-beta zeolite catalyst has been used for the oxidation of cyclic, secondary and primary alcohols in presence of hydrogen peroxide as the oxidizing agent [24].

The hydroxylation of phenol by using TS- 1 as the catalyst with hydrogen peroxide produces the ortho- and para-isomers of dihydroxybenzene [25]. The application of TS-1 as oxidation catalyst was first industrially realized process by Enichem Company for conversion of phenol [26]. Moreover, TS-1 has wide range of applications in food industries and fine chemical industries where the route of oxidation of catechol is an eco-friendly method [27].

The modeling and optimization of the oxidation reaction of catechol by using titanium silicate-1 has been done in this work which is not cited in literature till now. Kinetic model which is used here is an emipirical one. Statistical analysis of the data put a new light on this work.

The objective of the present study is to investigate the oxidation of catechol using commercial TS1 as catalyst and hydrogen peroxide (30\%) as oxidizing agent. The reaction is shown in Scheme 1.

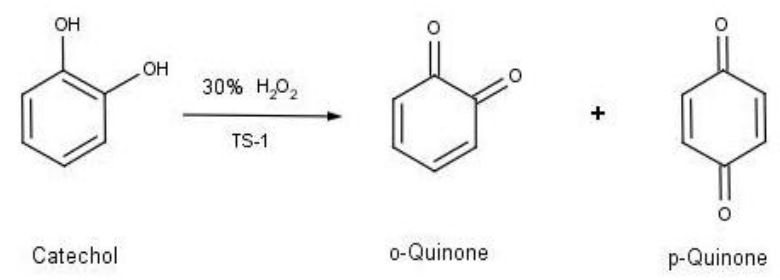

Scheme 1. Oxidation of catechol with TS-1 catalyst

The process is eco-friendly as no organic solvent is used. Catechol gives quinone after oxidation reaction. Quinone is an important organic compound, used mostly in the production of hydrogen peroxide, biochemicals, dye intermediates and other different organic reagents. The catalyst TS- 1 is characterised by using standard methods such as BET surface area analysis, XRD and SEM. The effects of different process parameters on conversion have also been studied. Response surface methodology
(RSM) with the Box-Behnken design with respect to three process parameters such as reaction temperature, moles of hydrogen peroxide per mole of catechol and catalyst amount is utilized for the optimization of conversion.

The Response Surface Methodology (RSM) is a statistical method, which is a useful technique for analyzing the process including the prediction of response which is under the influence of several variables and finally, the optimization of response variable through design of experiment (DOE). In this process, a series of preliminary experimental runs are conducted by changing the input variables in order to identify the ranges of the input variables and the reasons for changes in the output variable or response. The probable upper and lower limits of the input variables are determined. The minimum number of software prescribe experimental runs are to be conducted to generate the responses as function of different level of input variables. The data is to be fitted with a quadratic polynomial. The surface represented by a function of two input variables is called a response surface. The response can be represented either in the three-dimensional space with a particular shape of the response surface or as contour plots. The optimal design of experiments is the minimization of the objective function, which is a sum of square of deviation between model-predicted and experimental values.

\section{Experimental}

\subsection{Materials}

Catechol was purchased from Himedia Laboratories Pvt Ltd. India. Hydrogen peroxide (30\%, volume/volume) was supplied by Merck Specialities Pvt. Ltd., India. Titanium Silicate TS-1 (1.5mm extrudate) was supplied by Sud Chemie, Ltd., India.

\subsection{Apparatus and Experimental Procedure}

A three-necked cylindrical glass vessel of 150 $\mathrm{cm}^{3}$ volume and internal diameter $5.5 \mathrm{~cm}$ was used for the reaction. The vessel reactor is fitted with a glass stirrer, a thermometer and a reflux condenser. The whole arrangement is housed in a water-bath whose temperature was controlled with \pm $1{ }^{\circ} \mathrm{C}$ variation by using a digital controller cum indicator.

A typical experiment was carried out by using $0.0182 \mathrm{~mol}$ of catechol dissolved in $40 \mathrm{ml}$ water and $10 \mathrm{ml}$ hydrogen peroxide (30\%) $\left(0.1161 \mathrm{~mol} \mathrm{H}_{2} \mathrm{O}_{2}\right)$, using $0.5 \mathrm{~g}$ catalyst, at $40{ }^{\circ} \mathrm{C}$. The reaction mixture was stirred at $1000 \mathrm{rpm}$. The sample was withdrawn from the reaction mixture periodically and analysed using High Performance Liquid Chroma- 
tography (HPLC) equipped with an Agilent SB C18 column (length: $250 \mathrm{~mm}$, diameter: $4.6 \mathrm{~mm}$, packing size: $5 \mu$ ). The pump and detector used were Perkin Elmer Series 200 pump and Perkin Elmer Series 200 UV/VIS detector. The mobile phase used was a mixture of methanol and water $(1: 1 \mathrm{v} / \mathrm{v})$ at a flow rate of $1 \mathrm{ml} / \mathrm{min}$ and detection was performed at $280 \mathrm{~nm}$. The conversion of catechol was calculated by the following way: $X_{A}=\left(C_{A 0}-C_{A}\right) / C_{A 0}$, where, $X_{A}$ is the conversion, $C_{A 0}$ and $C_{A}$ are the initial and final concentration of reactant $\mathrm{A}$ in the reaction, respectively. The optimum reaction time for maximum conversion was determined, but as the byproduct formation (p-quinone) is so negligible, that the selectivity plot of the product is almost the same type as the conversion plot.

\subsection{Design of Experiment with Box-Behnken Method}

The conversion of catechol was optimized by response surface methodology (RSM) using BoxBehnken design with three effective variables such as, reaction temperature, A, moles of hydrogen peroxide per mole of catechol, B and catalyst amount, C by using statistical software Design-Expert 8.0.1. The response surface methodology with factorial design is an empirical optimization technique used to evaluate the relationship between a set of controllable experimental factors and observed results and it involves three major steps (i) performing statistically designed experiments, (ii) estimating the coefficients in a mathematical model, and (iii) predicting the response and checking the adequacy of the model [28-34]. Three independent variables with their levels of factorial design are presented in Table 1.

A quadratic statistical model was determined and optimized by fitting the experimental results through response surface methodology (RSM) to maximize the catechol conversion. The quadratic equation in general form which is widely used in statistical optimization process is as follows:

Table 1. Experimental range and levels of process variables

\begin{tabular}{lccc}
\hline \multirow{2}{*}{ Independent Variables } & \multicolumn{3}{c}{ Range and Levels } \\
\cline { 2 - 4 } & -1 & 0 & +1 \\
\hline Temperature, A $\left({ }^{\circ} \mathrm{C}\right)$ & 20 & 40 & 60 \\
Mole Ratio & 2.5 & 8.75 & 15 \\
$\left(\left(\mathrm{C}_{6} \mathrm{H}_{4}(\mathrm{OH})_{2}\right): \mathrm{n}\left(\mathrm{H}_{2} \mathrm{O}_{2}\right)\right)$, B & & & \\
$($ mole $/$ mole $)$ & & & \\
Catalyst amount, C $(\mathrm{g})$ & 0.10 & 0.80 & 1.5 \\
\hline
\end{tabular}

$$
z=\beta_{0}+\sum \beta_{i} x_{i}+\sum \beta_{i i} x_{i}^{2}+\sum \beta_{i j} x_{i} x_{j}
$$

where, $z$ is the response and $\beta_{o}, \beta_{i}, \beta_{i i}$, and $\beta_{i j}$ are coefficients of the intercept, linear, square and interaction effects, respectively. The parameters are $x_{1}=\mathrm{A}, x_{2}=\mathrm{B}$ and $x_{3}=\mathrm{C}$ as per in Table 1 . It is also possible to locate the region of interest where the desirable response (optimum condition) lies in, by simultaneous variation of several factors.

\section{Results and Discussion}

The commercial TS- 1 was used as the catalyst for the oxidation of catechol with $30 \% \mathrm{H}_{2} \mathrm{O}_{2}$ as an oxidizing agent. The products formed are two isomers, ortho-quinone (1,2 benzoquinone) and paraquinone ( 1,4 benzoquinone). Ortho-quinone is observed to be the major product between the two. Optimization of the process is done to find out the maximum conversion of the substrate and finally the optimal values of the selected process parameters were obtained accordingly. The commercial TS-1 catalyst was characterized and found that it possesses total surface area of $442.64 \mathrm{~m}^{2} / \mathrm{g}$ with average pore width $34.16 \AA$ and pore volume of 0.378 $\mathrm{cm}^{3} / \mathrm{g}$. Pore size distribution analysis shows that the majority of the pores in TS- 1 are below $20 \AA$. The adsorption-desorption data is given in the form of a hysteresis curve in the Figure 1(a). The $\mathrm{N}_{2}$ sorption isotherm of TS- 1 is of type I, which is the characteristic of a microporous zeolite. This observation is based on standard isotherm curves. The XRD and SEM analysis of the catalyst were also done. The XRD pattern of commercial TS-1, showed in Figure 1(b), proved high crystalinity and MFI type zeolite structure. The SEM image, shown in Figure 1(c), shows agglomerated granules of the catalyst; the particle size was estimated to be in

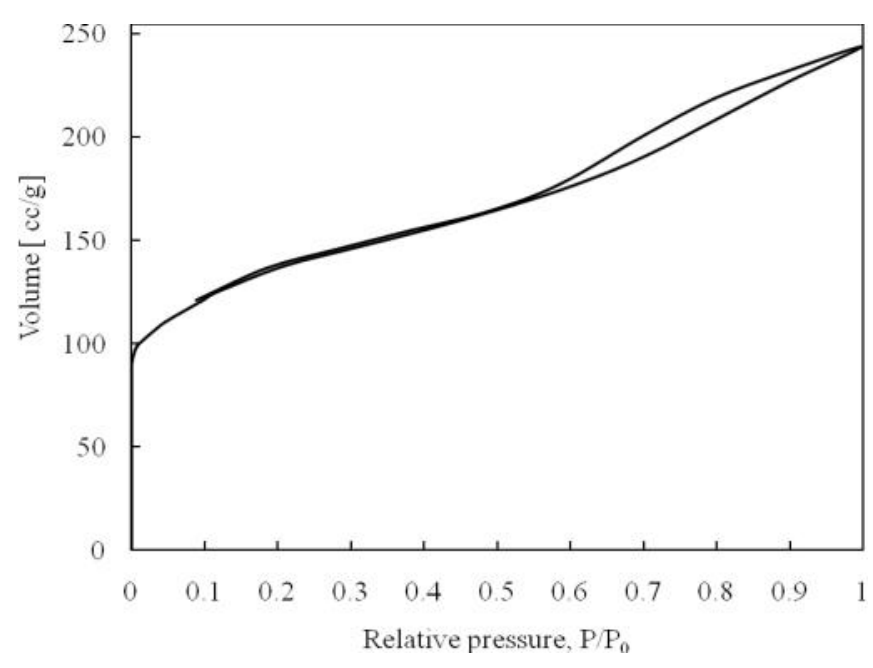

Figure 1(a). Adsorption desorption isotherm of TS-1 


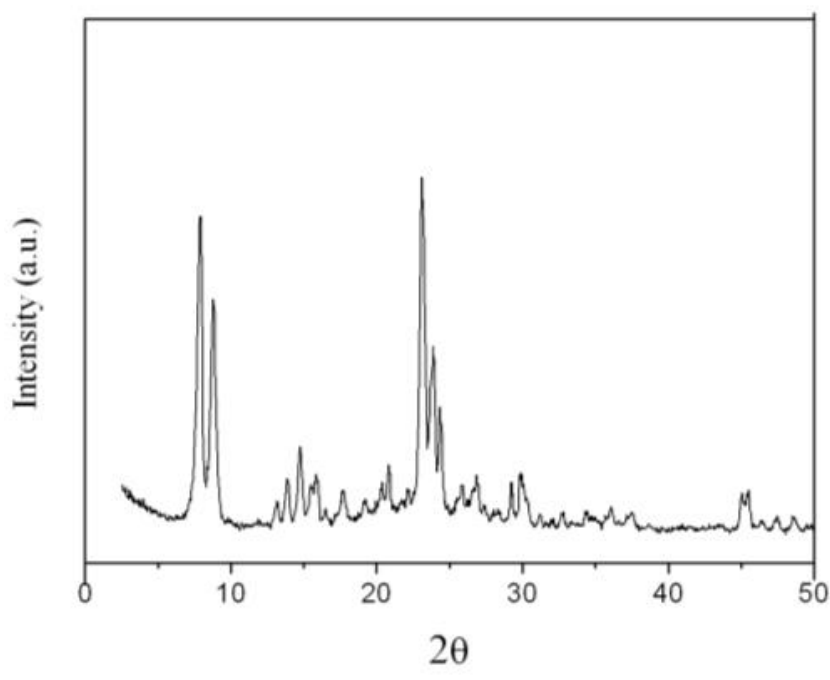

Figure 1(b). XRD pattern of commercial TS-1

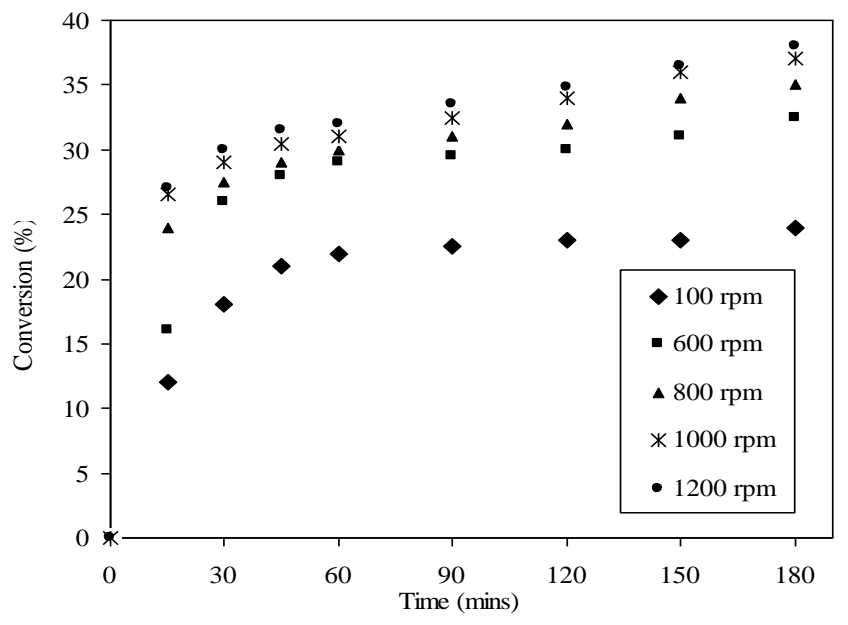

Figure 2. Influence of agitation speed (mole ratio of $\mathrm{H}_{2} \mathrm{O}_{2}$ to catechol : 5 , reaction time: $180 \mathrm{~min}$, temperature: $40{ }^{\circ} \mathrm{C}$, catalyst amount: $0.50 \mathrm{~g}$, catalyst particle size: $0.376 \mathrm{~mm}$, oxidizing agent: $30 \%$ aqueous $\mathrm{H}_{2} \mathrm{O}_{2}$, catalyst: TS-1)

the range of 125 to $250 \mathrm{~nm}$.

\subsection{Effect of variation of different parame- ters}

Speed of agitation, catalyst particle size, temperature, catalyst amount, mole ratio of hydrogen peroxide to catechol and reaction time are the main process parameters that affect the substrate conversion. The effects of these parameters on catechol conversion are shown in Figures (2)-(7).

\subsection{Influence of speed of agitation on conver- sion}

The effect of external mass transfer on the catechol oxidation was studied by varying stirrer speed

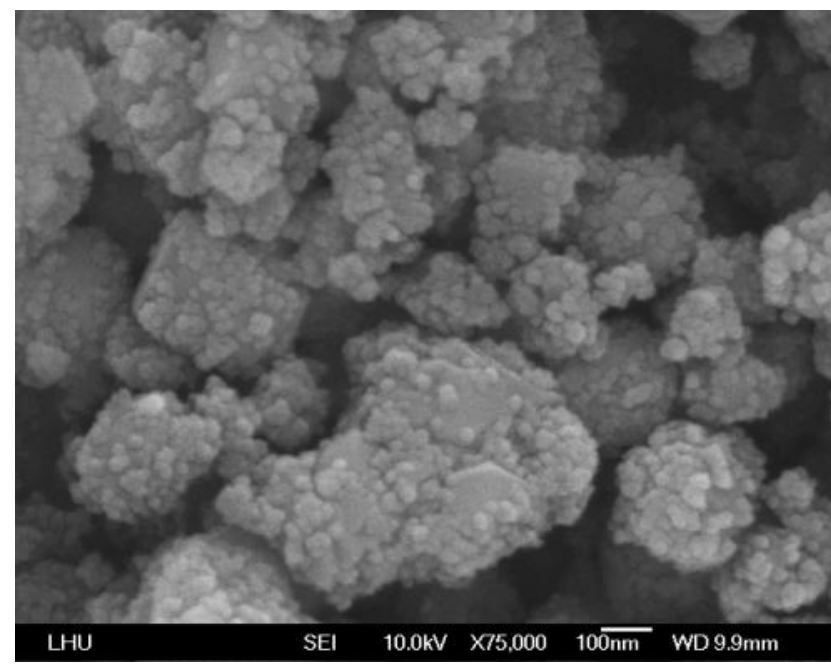

Figure 1 (c). SEM micrograph of commercial TS-1

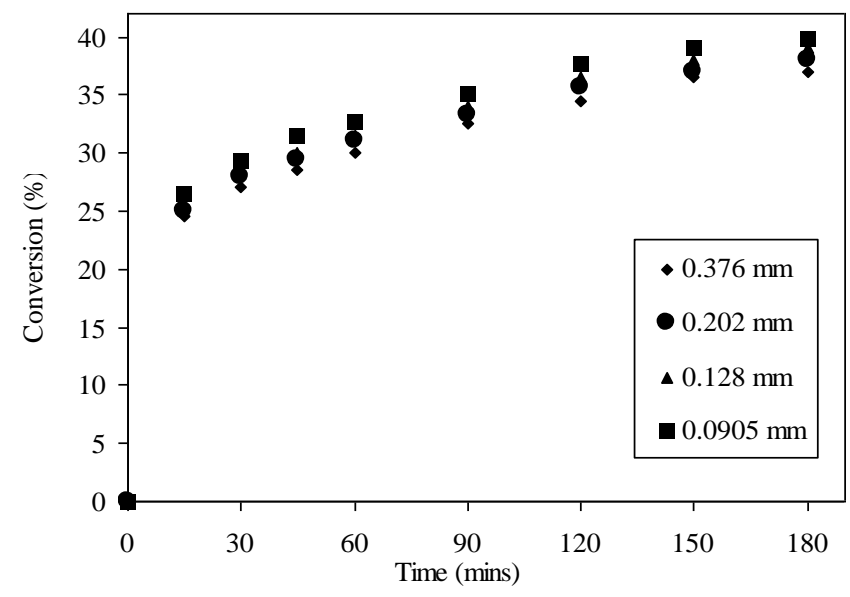

Figure 3. Variation of catalyst particle size (mole ratio of $\mathrm{H}_{2} \mathrm{O}_{2}$ to catechol : 5, reaction time: $180 \mathrm{~min}$, temperature: $40{ }^{\circ} \mathrm{C}$, agitation speed: $1000 \mathrm{rpm}$, catalyst amount: $0.50 \mathrm{~g}$, oxidizing agent: $30 \%$ aqueous $\mathrm{H}_{2} \mathrm{O}_{2}$, catalyst:TS-1)

from 100 to $1200 \mathrm{rpm}$. Figure 2 shows the time versus conversion of catechol at different stirrer speed keeping other process parameters, such as, reaction temperature, catalyst amount and moles of hydrogen peroxide to catechol constant. It depicts from the figure that the conversion of catechol using commercial TS-1 is found to be $37 \%$ and $39 \%$ at 1000 and $1200 \mathrm{rpm}$ respectively at reaction temperature $40{ }^{\circ} \mathrm{C}$ in $3 \mathrm{hr}$, thus the increase in the speed of agitation beyond $1000 \mathrm{rpm}$ has insignificant effect on the conversion. This supports the fact that at or above the stirrer speed $1000 \mathrm{rpm}$ all external mass transfer effects are negligible and the process is kinetically controlled. Hence all the subsequent experiments were carried out at 1000 
rpm. It has been observed that during the experiment, the particle size is not reducing with stirrer speed. Besides this, as the particle size is too small, the change in solid-liquid interfacial area is negligible with change in particle size. Hence, the effect of stirrer speed with variation of particle size was not undertaken.

\subsection{Variation of catalyst particle size}

The effect of variation of catalyst particle size on the conversion of catechol was studied by using different size of catalyst particles in the range of 0.0905 to $0.376 \mathrm{~mm}$ and the results are plotted in Figure 3. It is observed that particle size of the catalyst has an insignificant effect on the conversion of catechol and so the effect of internal mass transfer resistance may be neglected. Hence an average size of $0.376 \mathrm{~mm}$ was used in the subsequent reactions.

\subsection{Influence of temperature on reaction}

The effect of temperature on the conversion of catechol was studied by varying the temperature in the range of 20 to $70{ }^{\circ} \mathrm{C}$ by keeping the agitation speed at $1000 \mathrm{rpm}$, catalyst amount at $0.50 \mathrm{~g}$ and hydrogen peroxide to catechol mole ratio at 5:1.

Figure 4 shows the conversion of catechol with time by varying temperature from 20 to $70{ }^{\circ} \mathrm{C}$ and it has been observed that the conversion of catechol is highly influenced by the increase in temperature.

The conversion at 60 and $70{ }^{\circ} \mathrm{C}$ are found to be 50.5 and $51.6 \%$ in $180 \mathrm{~min}$ respectively and hence it is found that the increase in the reaction tem-

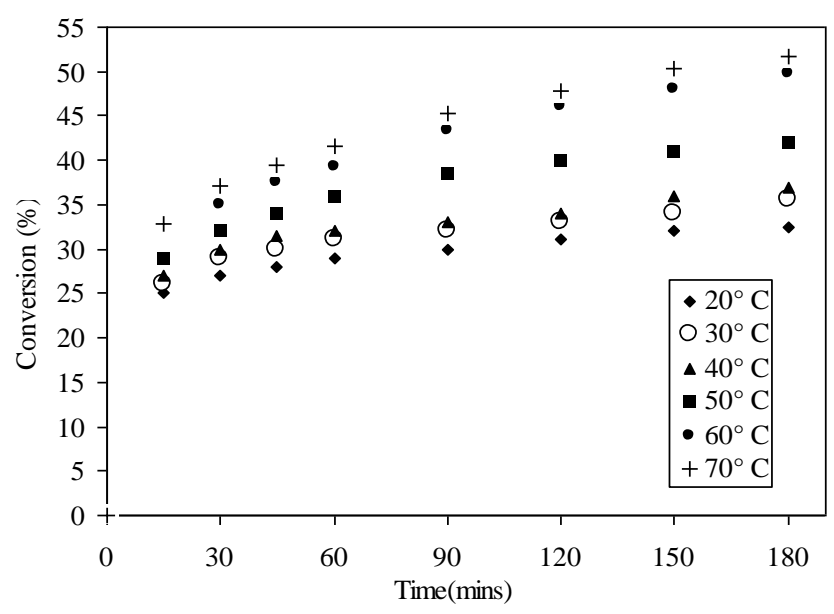

Figure 4. Temperature dependency of the reaction (mole ratio of $\mathrm{H}_{2} \mathrm{O}_{2}$ to catechol : 5, reaction time: $180 \mathrm{~min}$, agitation speed: $1000 \mathrm{rpm}$, catalyst amount: $0.50 \mathrm{~g}$, catalyst particle size: $0.376 \mathrm{~mm}$, oxidizing agent: $30 \%$ aqueous $\mathrm{H}_{2} \mathrm{O}_{2}$, catalyst: TS-1) perature beyond $60{ }^{\circ} \mathrm{C}$ has insignificant effect on the conversion. The reaction temperature beyond $60{ }^{\circ} \mathrm{C}$ has insignificant effect on reaction rate, which is probably due to the dissociation of hydrogen peroxide at higher temperature. Hence, $60{ }^{\circ} \mathrm{C}$ was chosen as the working reaction temperature for maximum conversion of catechol.

\subsection{Effect of variation of catalyst amount}

The effect of catalyst amount on the conversion of catechol was studied by varying the catalyst amount in the range of 0.1 to $1.5 \mathrm{~g}$ by keeping the agitation speed constant at $1000 \mathrm{rpm}$, reaction temperature at $40{ }^{\circ} \mathrm{C}$ and the mole ratio hydrogen peroxide to catechol at 5:1. Fig. 5 presents the results of variation of conversion of catechol at different catalyst amount and it is observed that the conversion of catechol is increasing by increasing the catalyst amount.

The increase in the concentration of active sites present on the catalyst surface with the increase in catalyst amount may be the reason of enhancement of conversion. The maximum conversion of catechol at $40{ }^{\circ} \mathrm{C}$ using commercial TS- 1 is found to be $51.5 \%$ with 1.5 g catalyst in $3 \mathrm{~h}$.

\subsection{Effect of mole ratio of hydrogen peroxide to catechol}

The effect of mole ratio of hydrogen peroxide to catechol on the conversion of catechol was studied by varying the mole ratio from $1: 2.5$ to $1: 20$ by keeping all other reaction parameters to be constant. The plot of conversion of catechol at different mole ratio is shown in Figure 6. From this figure, it

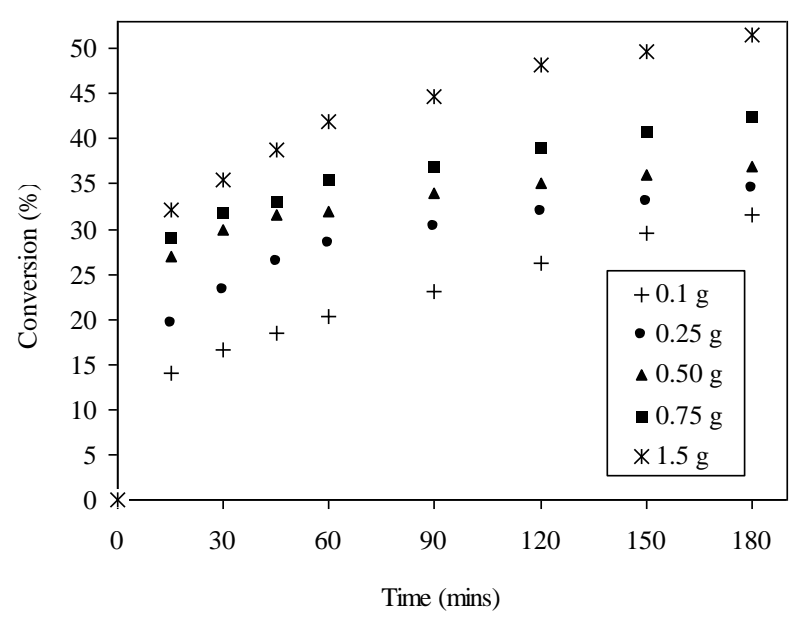

Figure 5. Variation of catalyst amount (Mole ratio of $\mathrm{H}_{2} \mathrm{O}_{2}$ to catechol : 5, reaction time: $180 \mathrm{~min}$, temperature: $40{ }^{\circ} \mathrm{C}$, agitation speed: $1000 \mathrm{rpm}$, catalyst particle size: $0.376 \mathrm{~mm}$, oxidizing agent: $30 \%$ aqueous $\mathrm{H}_{2} \mathrm{O}_{2}$, catalyst: TS-1) 
has been observed that the conversion of catechol is increased by increasing the mole ratio up to $15: 1$ and beyond that, no significant increase in conversion has been observed. This may be due to the non-availability of catechol at high hydrogen peroxide to catechol mole ratio. The maximum conversion of catechol using commercial TS- 1 is found to be $57.7 \%$ at a mole ratio of $15: 1$, at reaction temperature of $40{ }^{\circ} \mathrm{C}$, catalyst amount $0.50 \mathrm{~g}$ and stirrer speed of $1000 \mathrm{rpm}$ at $3 \mathrm{~h}$ Therefore, the mole ratio $15: 1$ was chosen to be the optimum for catechol conversion.

\subsection{Selection of reaction time span}

The suitable reaction time economical to the process for obtaining maximum conversion of catechol was determined by continuing the reaction till $240 \mathrm{~min}$, keeping the agitation speed at $1000 \mathrm{rpm}$, reaction temperature $60{ }^{\circ} \mathrm{C}$, catalyst amount $0.5 \mathrm{~g}$ and mole ratio 5:1 and the result is shown in Figure 7. It is observed that the conversion of catechol is increased as the reaction time increases and there is a very little increase in conversion from 180 to $240 \mathrm{~min}$ (50.5 to $51.5 \%$ ). Thus, it is not fruitful to further increase the reaction time. Moreover, $\mathrm{H}_{2} \mathrm{O}_{2}$ is unstable, thus extending the reaction time beyond $180 \mathrm{~min}$ is not advisable for the reaction. Hence 180 min was chosen as the optimum reaction time and all further experiments were carried out up to $180 \mathrm{~min}$.

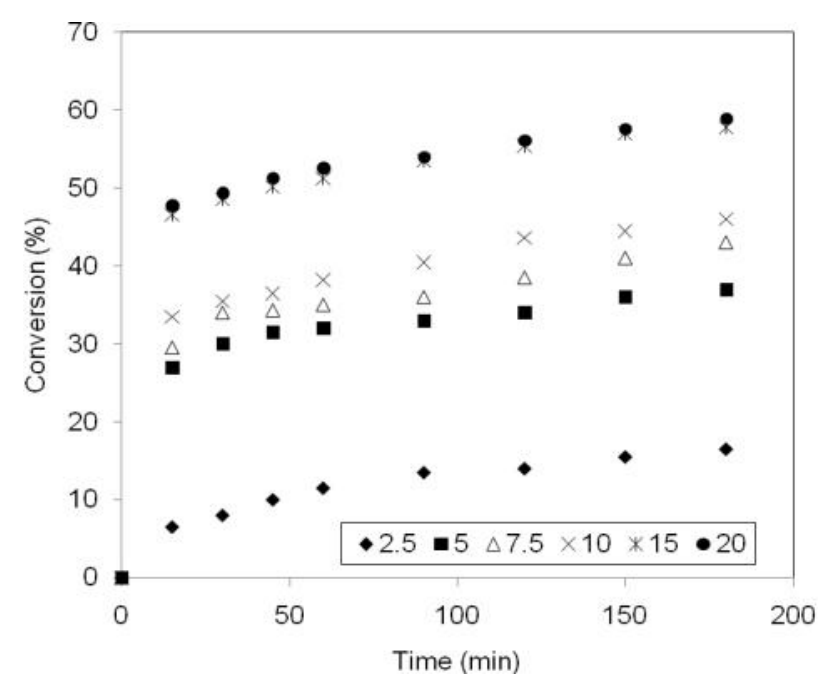

Figure 6. Influence of mole ratio of $\mathrm{H}_{2} \mathrm{O}_{2}$ to catechol. (Reaction time: $180 \mathrm{~min}$, temperature: 40 ${ }^{0} \mathrm{C}$, agitation speed: $1000 \mathrm{rpm}$, catalyst amount: $0.50 \mathrm{~g}$, catalyst particle size: $0.376 \mathrm{~mm}$, oxidizing agent: $30 \%$ aqueous $\mathrm{H}_{2} \mathrm{O}_{2}$, catalyst: TS-1)

\section{Optimization by Box-Behnken design}

A Box-Behnken design was used for optimization of conversion of catechol in order to establish the relationship between the input process parameters and reaction conversion. The input parameters for the optimization was chosen to be reaction temperature, $\mathrm{A}$, moles of hydrogen peroxide per mole of catechol, B and catalyst amount, C. The Box-Behnken design [35] suggested 15 random experiments with respect to the input process parameters. The response as a function of three dependent process parameters was obtained by fitting the experimental data and it was given in the form of quadratic equation using the statistical analysis (Design-Expert 8.0.1 software).

$$
\begin{aligned}
& Z=43.6+8.14 A+19.18 B+7.24 C+0.08 A^{2}-3.57 B^{2} \\
& +1.95 C^{2}+4.53 A B+3.2 A C+1.92 B C
\end{aligned}
$$

Table 2 shows the results of analysis of variance (ANOVA). The F-value for the regression model was found to be 218.16 which is much higher than the critical F-value $\mathrm{F}_{95}, 0.05$. It shows that the model is more significant. However, the F-statistics values for all regressions were found to be higher which signifies that any variations in the response can be explained by the predicted model equation. The corresponding P-values in the Table 3 are used to analyze whether the F-statistics values are sufficient enough to explain statistical significance be-

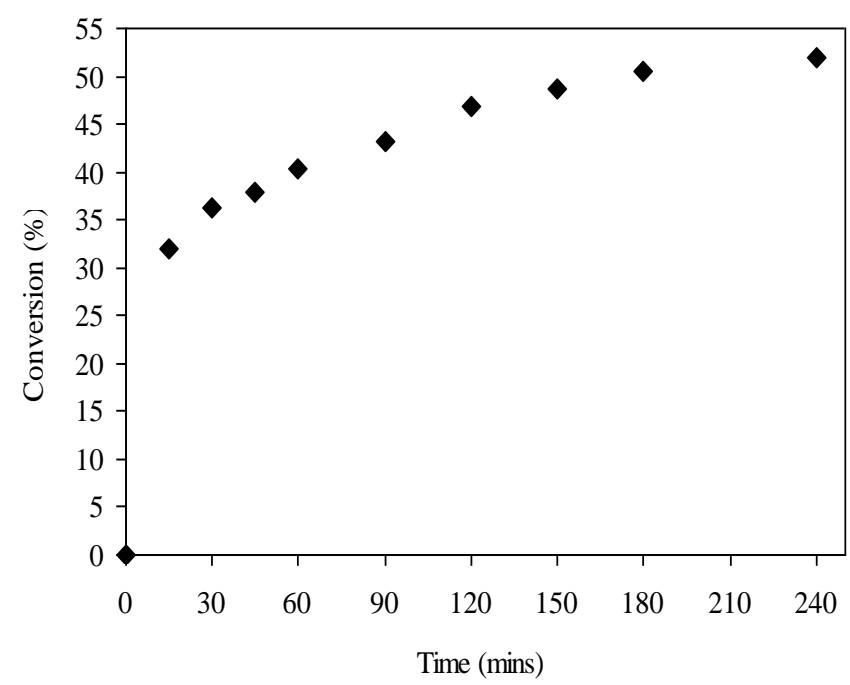

Figure 7. Influence of reaction time (mole ratio of catechol to $\mathrm{H}_{2} \mathrm{O}_{2}: 1: 5$, temperature: $60^{\circ} \mathrm{C}$, agitation speed: $1000 \mathrm{rpm}$, catalyst amount: $0.50 \mathrm{~g}$, catalyst particle size: $0.376 \mathrm{~mm}$, oxidizing agent: $30 \%$ aqueous $\mathrm{H}_{2} \mathrm{O}_{2}$, catalyst: TS-1) 
tween the predicted and actual response [35]. A Pvalue less than 0.05 indicate the significance of the model. It may be concluded that, the terms A, B, C, $\mathrm{AB}, \mathrm{AC}, \mathrm{BC}, \mathrm{B}^{2}$ and $\mathrm{C}^{2}$ are significant parameters as all $\mathrm{P}$-values are lower than 0.05 and the confidence level is $95 \%$. The amount of deviation in the response is shown by the residual error in Table 3 . A comparison between the experimental and predicted conversion $\mathrm{Z}_{\text {expt }}$ and $\mathrm{Z}_{\text {pred }}$ respectively are plotted in Figure 8 and a $45^{\circ}$ line passing through origin fitted with a correlation coefficient of 0.9987 and this indicates that the predicted response correlates well with the experimental analysis.

A very high $\mathrm{R}$-Squared (R-Sq) value of 0.9975 indicates that the predicted regression model is sufficiently accurate to explain the original relationship between the response and the process parameters.

\subsection{Response surface plots}

Response surfaces can be visualized in the form of 3-D surface plots that represent the variation of the response with two variables, keeping the other parameter fixed. The resulting response 3D surface plots for the catechol conversion is a function of (a) temperature and mole ratio (b) temperature and catalyst amount (c) mole ratio and catalyst amount which are shown in Figures 9a, 9b and 9c respectively. The central point $(\mathrm{CP})$ or stationary point is the point at which slope of the contour is zero in all possible directions. The coordinates of the $\mathrm{CP}$ within the maximum contour levels in each of the given figures represent the optimum values of the respective parameters. The maximum predicted conversion lies in the surface confined in the smallest curve of the 3D contour diagram.

\subsection{Optimization and selection of optimum conditions}

Optimization of the response was performed numerically by statistical tool. The optimization presented in Table 3 shows the optimum values of the process parameters for attaining the highest conversion. The optimum values of catechol conversion are obtained by fixing the starting values of the independent variables: temperature $\left(60{ }^{\circ} \mathrm{C}\right)$, mole ratio of $\mathrm{H}_{2} \mathrm{O}_{2}$ and catechol (2.5) and catalyst amount $(0.80 \mathrm{~g})$. The optimum conversion $(\mathrm{Z})$ was obtained as $75.84 \%$ at the optimum temperature as $60{ }^{\circ} \mathrm{C}$, moles of hydrogen per oxide per mole of as 13.20

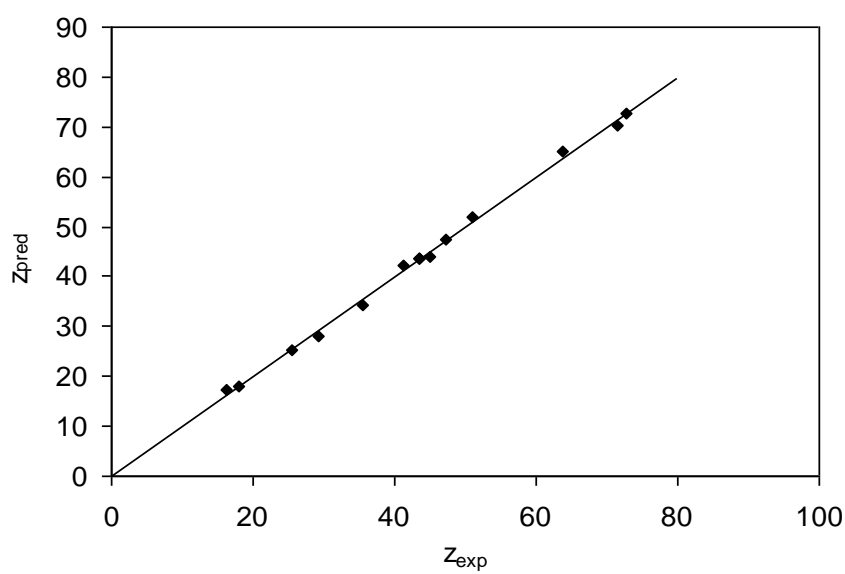

Figure 8. Comparison between experimental and predicted conversion

Table 2. Analysis of variance (ANOVA) for conversion

\begin{tabular}{cccccc}
\hline Source & DF & SS & MSE & F & p (Prob>F) \\
\hline Model & 9 & 4096.64 & 455.18 & 218.16 & $<0.0001$ \\
A & 1 & 529.75 & 529.75 & 253.89 & $<0.0001$ \\
B & 1 & 2941.44 & 2941.44 & 1409.75 & $<0.0001$ \\
C & 1 & 419.05 & 419.05 & 200.84 & $<0.0001$ \\
AB & 1 & 81.90 & 81.90 & 39.25 & 0.0015 \\
AC & 1 & 40.96 & 40.96 & 19.63 & 0.0068 \\
BC & 1 & 14.82 & 14.82 & 7.10 & 0.0446 \\
A $^{2}$ & 1 & 2.36 & 4.36 & 1.13 & 0.3359 \\
B $^{2}$ & 1 & 47.19 & 14.04 & 22.62 & 0.0051 \\
C & 1 & 14.04 & 2.09 & - & 0.0486 \\
Residual & 5 & 10.43 & 3.48 & - & - \\
Lack of fit & 3 & 10.43 & 0 & - & - \\
Pure Error & 2 & 0 & & -
\end{tabular}


mol and catalyst amount as $1.24 \mathrm{~g}$. Thus the RSM was successfully applied to maximize the catechol conversion for oxidation reaction using $\mathrm{H}_{2} \mathrm{O}_{2}$ as an oxidizing agent. A typical experimental reaction was performed with the optimum parametric condition obtained by RSM and the conversion (73.52 $\%)$ obtained was close to the optimum value.

\subsection{Kinetics of catechol oxidation with $\mathrm{H}_{2} \mathrm{O}_{2}$}

In addition with statistical optimization, a systematic kinetic study is also important. The oxidation of catechol is a heterogeneous reaction where the liquid phase comprises a mixture of catechol and aqueous solution of $\mathrm{H}_{2} \mathrm{O}_{2}$ and TS- 1 catalyst is the solid phase. The effects of mass transfer have been minimized with reasonable agitation speed and appropriate size of catalyst particles to make the reaction kinetically controlled. The reaction kinetics was studied at three different temperatures: 20,40 and $60^{\circ} \mathrm{C}$.

The rate model for the present heterogeneous reaction was derived based on the dual site Langmuir-Hinshelwood mechanism assuming surface reaction as the rate determining step [36]. The overall reaction may be written as

$$
\mathrm{C}_{6} \mathrm{H}_{6} \mathrm{O}_{2}(\mathrm{~A})+\mathrm{H}_{2} \mathrm{O}_{2}(\mathrm{~B}) \rightarrow \mathrm{C}_{6} \mathrm{H}_{4} \mathrm{O}_{2}(\mathrm{C})+2 \mathrm{H}_{2} \mathrm{O}
$$

Adsorption step: ( $\mathrm{S}$ is the active site)

$$
\begin{aligned}
A+S & \Leftrightarrow A . S \\
B+S & \Leftrightarrow B . S
\end{aligned}
$$

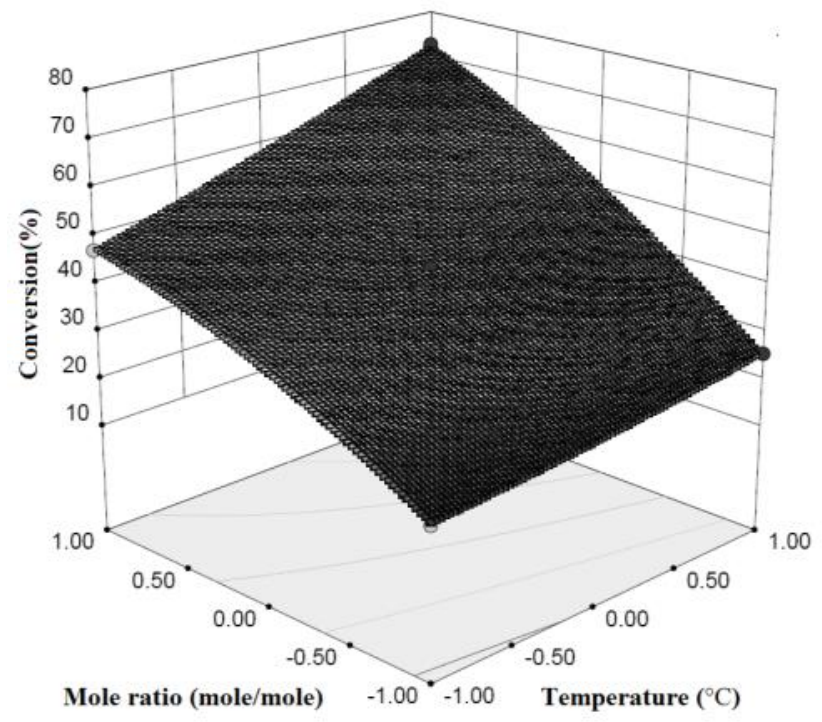

Figure 9a. Surface plot of conversion as a function of temperature and mole ratio
Surface reaction: (rate limiting)

$$
A . S+B . S \rightarrow C . S+D . S
$$

Desorption step:

$$
\begin{gathered}
C . S \Leftrightarrow C+S \\
D+S \Leftrightarrow D+S
\end{gathered}
$$

The reaction rate for species A may be written as:

$$
-r_{A}=\frac{m k K_{A} K_{B} C_{A} C_{B}}{\left(1+K_{A} C_{A}+K_{B} C_{B}\right)^{2}} \quad \text { gmol.min }{ }^{-1} \mathrm{~L}^{-1}
$$

where, $k$ is the rate constant; $K_{A}$ and $K_{B}$ are the equilibrium adsorption constants (L.gmol-1) for species $\mathrm{A}$ and $\mathrm{B}$ respectively. $C_{A}$ and $C_{B}$ are the concentrations (gmol. $\mathrm{L}^{-1}$ ) of species $\mathrm{A}$ and $\mathrm{B}$ in reaction mixture respectively. Where, $\mathrm{m}$ is the catalyst loading. The concentration of a species in a biphasic system is according to their moles in their respective phases. As all the reactions were carried out at constant catalyst loading $(0.5 \mathrm{~g})$, hence, the weight of the catalyst is associated with the rate constant. The rate of reaction $\left(-r_{A}\right)$ for the case of small amount of powdered catalyst suspended in a liquid may be expressed in terms of slurry volume.

Equation (3) can be written in terms of conversion $\left(X_{A}\right)$ as:

$$
\begin{aligned}
\frac{d X}{d t} & =\frac{m C_{A 0} k K_{A} K_{B}\left(1-X_{A}\right)\left(M-X_{A}\right)}{\left[1+K_{A} C_{A 0}\left(1-X_{A}\right)+K_{B} C_{A 0}\left(M-X_{A}\right)\right]^{2}} \\
\frac{d X}{d t} & =\frac{k^{\prime}\left(1-X_{A}\right)\left(M-X_{A}\right)}{\left[1+k_{2}\left(1-X_{A}\right)+k_{3}\left(M-X_{A}\right)\right]^{2}}
\end{aligned}
$$

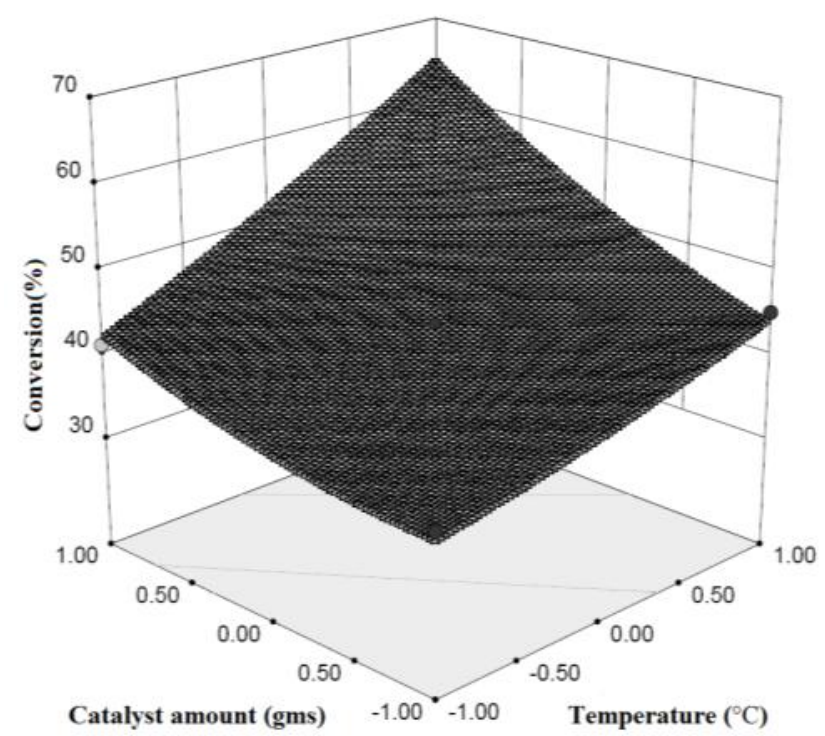

Figure 9b. Surface plot of conversion as a function of catalyst amount and temperature 
where, $k^{\prime}=m C_{A o} k K_{A} K_{B}, k_{2}=C_{A o} K A, k_{3}=C_{A 0} K_{B}$ and $\mathrm{M}=\mathrm{C}_{\mathrm{Bo}} / \mathrm{C}_{\mathrm{Ao}}=5$

Equation (3a) was fitted with non-linear method of analysis by using Matlab 7.1 software. The value of the parameter $k_{2}$ was found to be negative at 20 ${ }^{\circ} \mathrm{C}$ and $k_{3}$ is negative at 40 and $60{ }^{\circ} \mathrm{C}$ and large values of mean square error were noted.

The results of the non-linear estimation of parameters of Equation (3a) are shown in Table 4. As the values at all temperatures are found to be negative, hence, the model represented by Equation (3a) is rejected. So, an empirical rate equation of the following form has been attempted.

$$
-r_{A}=\frac{-d C_{A}}{d t}=k_{1} C_{A} C_{B}
$$

where, $\mathrm{k}_{1}$ is in $\mathrm{L}^{-1} \mathrm{gmol} \mathrm{min}^{-1}$

As the amount of $\mathrm{H}_{2} \mathrm{O}_{2}$ was taken in excess and the change in concentration of $\mathrm{H}_{2} \mathrm{O}_{2}$ in comparison to catechol is negligible, rate is considered to be independent of $C_{B}$. Hence, the reaction may be considered as pseudo first order with respect to the catechol concentration $\left(C_{A}\right)$. Hence, Eq. (4) may be simplified as:

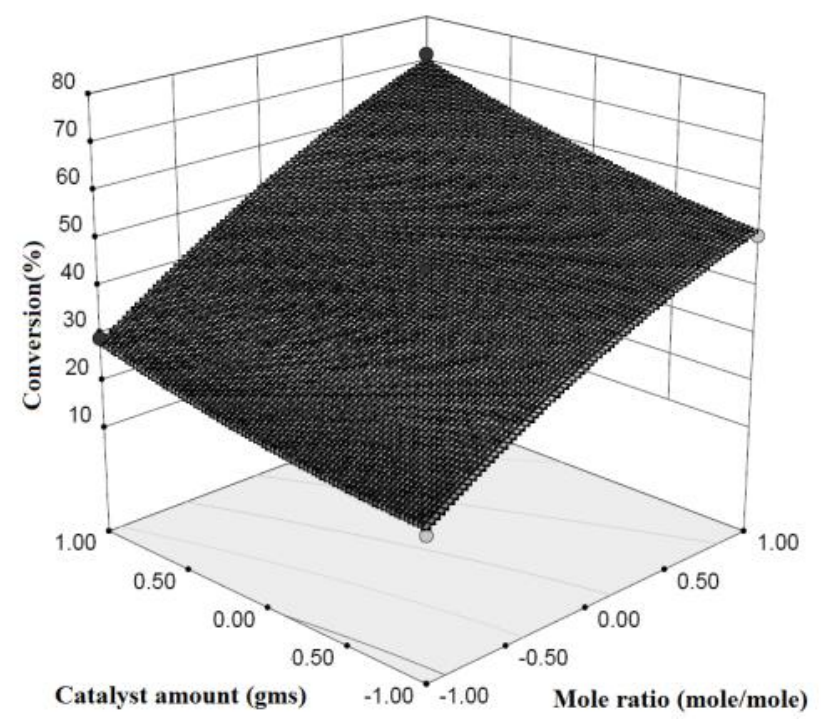

Figure 9c. Surface plot of conversion as function of catalyst amount and mole ratio

Table 3. Results of optimization of conversion

\begin{tabular}{llll}
\hline \multicolumn{1}{c}{ Parameter } & $\begin{array}{r}\text { Coded } \\
\text { Value }\end{array}$ & $\begin{array}{c}\text { Actual } \\
\text { values }\end{array}$ & $\begin{array}{c}\text { Exp. } \\
\text { values }\end{array}$ \\
\hline Conversion, \% & - & 75.842 & 73.52 \\
Temperature, ${ }^{\circ} \mathrm{C}$ & +1.00 & 60.00 & 60.00 \\
Mole ratio & +0.71 & 13.20 & 13.20 \\
Catalyst loading, g & +0.63 & 1.24 & 1.24 \\
\hline \multicolumn{2}{l}{ Composite desirability $=1.000$} & & \\
\hline
\end{tabular}

$$
-r_{A}=-\frac{d C_{A}}{d t}=k_{0} C_{A}
$$

where $k_{o}=$ apparent rate constant $=k_{1} . C_{B o} \mathrm{~min}^{-1}$

Equation (4) is integrated with limits for $t=0$, $C_{A}=C_{A o}$ to $t=t, C_{A}=C_{A}$, on integration of Equation (5)

$$
-\ln \frac{C_{A}}{C_{A_{0}}}=k_{0} . t
$$

or,

$$
\ln \left(\frac{1}{1-X_{A}}\right)=k_{0} . t
$$

where $X_{A}=$ fractional conversion of reactant species A at time $t=s$.

The plot of $\ln \left(1 / 1-X_{A}\right)$ versus time at different temperatures gives a linear plot as shown in Figure 10 . The apparent rate constant $k_{o}$ was calculated from the slope of the straight line and fitted to the Arrhenius plot as shown in Figure 11. The apparent activation energy and the frequency factor were found to be $11.37 \mathrm{~kJ} / \mathrm{mole}$ and $37.08 \mathrm{~min}^{-1}$ respectively.

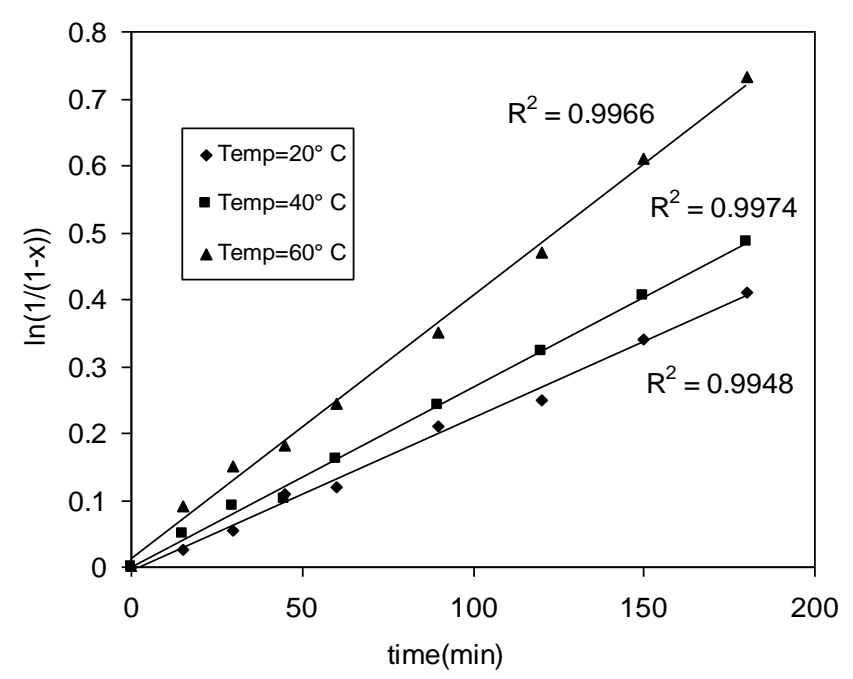

Figure 10. Fitting of kinetic data pseudo first order rate equation

Table 4. Results of the analysis of Equation 3a

\begin{tabular}{ccccc}
\hline \multirow{2}{*}{$\begin{array}{c}\text { Temp. } \\
{ }^{\circ} \mathrm{C}\end{array}$} & \multicolumn{3}{c}{$\begin{array}{c}\text { Parameters } \\
(\mathrm{X} \mathrm{10-2)}\end{array}$} & $\begin{array}{c}\text { MSE } \\
\text { x 10 }\end{array}$ \\
\cline { 2 - 4 } & $k$ & $k_{2}$ & $k_{3}$ & \\
\hline 20 & 0.0048 & -5.154 & 0.938 & 5.77 \\
40 & 0.1346 & 20.718 & -3.718 & 9.17 \\
60 & 0.0049 & 3.774 & -0.68 & 16.21 \\
\hline
\end{tabular}




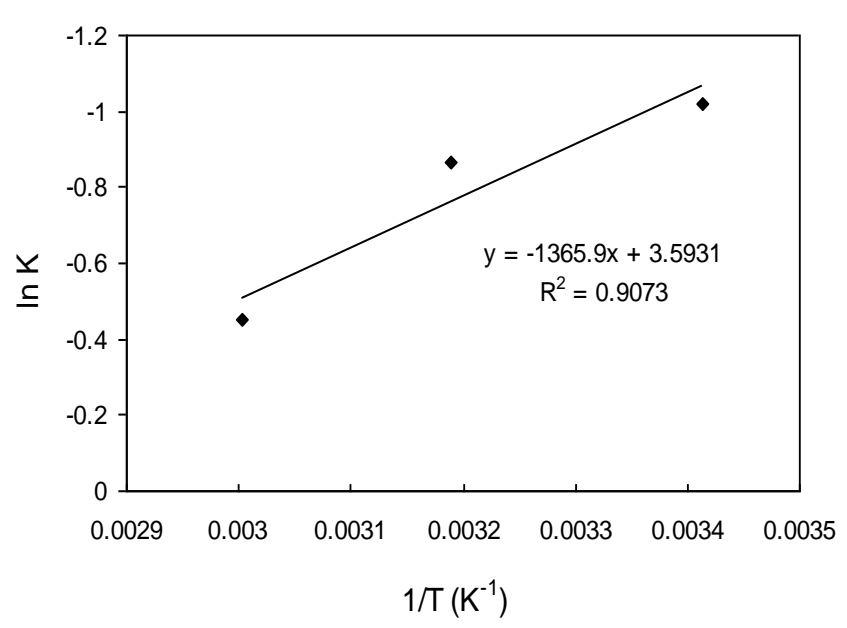

Figure 11. Arrhenius plot

\section{Conclusion}

The oxidation of catechol was carried out by using titanium silicate- 1 as catalyst with $30 \%$ hydrogen peroxide as oxidizing agent. The process is ecofriendly as no organic solvent is used. The process was optimized by using response surface methodology by employing Box-Behnken design and a second order quadratic equation in terms of three independent process variables such as reaction temperature, moles of hydrogen peroxide per mole of catechol and catalyst amount for the design of experiment was formed. The large value of correlation coefficient as 0.9987 indicates that the predicted response correlates well with the experimental values. The optimum values were, temperature: $60{ }^{\circ} \mathrm{C}$, hydrogen peroxide to catechol: 13.2 and catalyst amount: $1.24 \mathrm{~g}$ to achieve a maximum conversion of $75.842 \%$. A pseudo first order kinetic rate equation was proposed for the reaction. The activation energy and the frequency factor were found to be $11.37 \mathrm{~kJ} / \mathrm{mole}$ and $37.08 \mathrm{~min}^{-1}$ respectively.

\section{References}

[1] Sheldon, R. A. (1996). Selective catalytic synthesis of fine chemicals: opportunities and trends. Journal of Molecular Catalysis A: Chemical, 107: 7583.

[2] Rafelt, J.S., Clark, J. H. (2000). Recent advances in the partial oxidation of organic molecules using heterogeneous catalysis. Catalysis Today, 57: 3334.

[3] Sheldon, R. A. (2008). E factors, green chemistry and catalysis: An odyssey. Chemical Communication, 29: 3352-3365.

[4] Mukherjee, P., Bhaumik, A., Kumar, R. (2007). Eco-friendly, Selective Hydroxylation of C-7 Aro- matic Compounds Catalyzed by TS- $1 / \mathrm{H}_{2} \mathrm{O}_{2}$ System under Solvent-free Solid-Liquid-Liquid-Type Triphase Conditions. Industrial and Engineering Chemistry Research, 46: 8657-8664.

[5] Sherman, J. D. (1999). Synthetic zeolites and other microporous oxide molecular sieves. Proceedings of National Acadamy of Science, 96: 3471-3478.

[6] Notari, B. (1996). Microporous Crystalline Titanium Silicates. Advance Catalysis, 41: 253-334.

[7] Ratnasamy, P., Srinivas, D., Knözinger, H. (2004). Active Sites and Reactive Intermediates in Titanium Silicate Molecular Sieves. Advance Catalysis, 48: 1-169.

[8] Vayssilov, G. N., Popova, Z., Tuel, A. (1997). Catalytic Oxidation of Anisole Over Titanium Silicalite- 1. Chemical Engineering and Technology, 20: 333-337.

[9] Gao, H., Lu, G., Suo, J., Li, S. (1996). Epoxidation of allyl chloride with hydrogen peroxide catalyzed by titanium silicalite 1. Applied Catalysis: General, 138: 27-38.

[10] Esposito, A., Taramasso, M., Neri, C. (1983). Enichem, U.S. Patent 4; 396, 783.

[11] Clerici, M. G. (1991). Oxidation of saturated hydrocarbons with hydrogen peroxide catalysed by titanium silicalite. Applied Catalysis, 68: 249-261.

[12] Mantegazza, M. A., Petrini, G., Spano, G., Bagatin, R., Rivetti, F. (1999). Selective oxidations with hydrogen peroxide and titanium silicalite catalyst. Journal of Molecular Catalysis A: Chemical, 146: 223-228.

[13] Maspero, F., Romano, U. (1994). Oxidation of alcohols with $\mathrm{H}_{2} \mathrm{O}_{2}$ catalysed by titanium silicate-1. Journal Catalysis, 146: 476-482.

[14] Reddy, J.S., Jacobs, P.A. (1996). Selective oxidation of secondary amines over titanium silicalite molecular sieves, TS- 1 and TS-2. Catalysis Letter, 37: 213-216.

[15] Robinson, D.J., Davies, L., McGuire, N., Lee, D. F., McMorn, P., Willock, D. J., Watson, G. W., Page, P. C. B., Bethell , D., Hutchings, G. (2000). Oxidation of thioethers and sulfoxides with hydrogen peroxide using TS-1 as catalyst. Journal of Physical Chemistry, 2: 1523-1529.

[16] Prasad, M.R., Kamalakar, G., Madhavi, G., Kulkarni, S.J., Raghavan, K.V. (2002). An efficient synthesis of heterocyclic $N$-oxides over molecular sieve catalysts. Journal Molecular Catalysis A: Chemical, 186: 109-120.

[17] van der Pol, A.J.H.P., van Hoof, J.H.C. (1993). Oxidation of linear alcohols with hydrogen peroxide over titanium silicate-1. Applied Catalysis A: General, 106: 97-113.

[18] Hitomi, Y., Ando, A., Matsui, H., Ito, T., Tanaka, 
T.,. Ogo, S., Funabiki T. (2005). Aerobic Catechol Oxidation Catalyzed by a $\operatorname{Bis(i-oxo)dimanganese}$ (III,III) Complex via a Manganese(II) Semiquinonate Complex. Inorganic Chemistry, 44: 3473-3478.

[19] Jackson, H. (1939). The oxidation of catechol and 1:2 :4-trihydroxybenzene by polyphenol oxidase. Journal of Biochemistry, 33(9): 1452-1459.

[20] Wegner, R., Gottschaldt, M., Görls,H., Jäger, E.Klemm, D. (2001). Copper(II)Complexesof Aminocarbohydrate b-Ketoenaminic Ligands: Efficient Catalysts in Catechol Oxidation. Chemistry A European Journal, 7(10): 2143-2157.

[21] Louloudi, M., Mitopoulou, K., Evaggelou, E., Deligiannakis, Y., Hadjiliadis, N. (2003). Homogeneous and heterogenized copper (II) complexes as catechol oxidation catalysts. Journal of Molecular Catalysis A: Chemical, 198: 231-240.

[22] Chittilappilly, P. S., Sridevi N., Yusuff, K.K.M. (2008). Ruthenium complexes of Schiff base ligands as efficient catalysts for catecholhydrogen peroxide reaction Journal of Molecular Catalysis A: Chemical, 286: 92-97.

[23] Khouw, C., Dartt, C. B., Labinger, J.A., Davis, M. E. (1994). Studies on the catalytic oxidation of alkanes and alkenes by titanium silicates. Journal of Catalysis, 149: 195-205.

[24] Corma A., Esteve, P., Martinez, A. (1996). Kinetics of the oxidation of alcohols by hydrogen peroxide on Ti-beta zeolite: the influence of alcohol structure on catalyst reactivity. Applied Catalysis A: General., 143: 87-100.

[25] Wroblewska, A., Fajdek, A., Milchert, E. (2009). Synthesis and characteristics of titanium silicalite TS-1, Ti-Beta and Ti-MWW catalysts. Journal of Chemical Technology, 11(1) : 64-71.

[26] Martens, J., Buskens, P., Jacobs, P., van der Pol A.J.H.P., van Hooff, J.H.C., Ferrini C., Kouwenhoven H., Kooyman P., van Bekkum H. (1993). Hydroxylation of phenol with hydrogen peroxide on EUROTS-1 catalyst. Applied Catalysis, 99 :7184.

[27] Ramaswamy, A.V., Sivasanker, S. (1993). Selective oxidation reactions over titanium and vana- dium metallosilicate molecular sieves. Catalysis Letter, 22: 239-249.

[28] Daroux, M., Zamani, H., Greffe J. L., Bordet,J. (1981). Use of Factorial Design of Experiments in Bulk Polymerization of Styrene. Chemical Engineering Journal, 22: 125-132.

[29] Ravikumar, K., Pakshirajan, K., Swaminathanc, T., Balu, K. (2005). Optimization of batch process parameters using response surface methodology for dye removal by a novel adsorbent. Chemical Engineering Journal, 105: 131-138.

[30] Büyüksönmez, F, Hess T.F., Crawford R.L., Paszczynski A., Watts R. J. (1999). Optimization of Simultaneous Chemical and Biological Mineralization of Perchloroethylene. Journal of Applied Environmental Microbiology, 65: 2784-2788.

[31] Jose N., Sengupta S., Basu J.K. (2011). Optimization of oxidative desulfurization of thiophene using $\mathrm{Cu}$ /titanium silicate- 1 by box-behnken design. Fuel, 90(2): 626-632.

[32] Ferreira, S.L.C., Bruns, R.E., Ferreira, H.S., Matos, G.D. , David, J.M., Brand ao, G.C. , da Silva, E.G.P., Portugal, L.A., dos Reis, P.S., Souza, A.S., dos Santos, W.N.L. (2007). BoxBehnken design: An alternative for the optimization of analytical methods. Analytica Chimica Acta, 597: 179-186.

[33] Raoof, J. B., Kiani, A., Ojani R., Sakhavi, F., Hamidi, A.S. (2010). Potentiometric effect of Lpenicillamine on a belousov-zhabotinskii oscillating chemical reaction: Application to determination of L-penicillamine. Analytical \& Bioanalytical. Electrocheistry :2(4),189-201.

[34] Cui, S., Ma F., Wang Y. (2007). Oxidative desulfurization of model diesel oil over Ti-containing molecular sieves using hydrogen peroxide Reaction Kinetics \& Catalysis Letter, 92(1): 155-163.

[35] Montgomery, D. C., (1991). Design and Analysis of Experiments, 3rd ed., Wiley: NewYork.

[36] Fogler, H. S. (2006). Elements of Chemical Reaction Engineering; $4^{\text {th }}$ ed., Prentice-Hall. 